\title{
Diversity and Performance of Sulphate-Reducing Bacteria in Acid Mine Drainage Remediation Systems
}

\author{
Enoch A. Akinpelu, Elvis Fosso-Kankeu, Frans Waanders, \\ Justine O. Angadam, and Seteno K. O. Ntwampe
}

\begin{abstract}
Microbial diversity in acid mine drainage from eMalahleni, Mpumalanga, South Africa. Enrichment of SRB improves its performance in sulphate reduction. Microbial community shows synergy between SRB Proteobacteria and facultative Bacilli. Sulphate reduction of $85 \%$ and cadmium reduction of $98 \%$ were observed within 7 days of continuous operational mode. The microbial community showed wider substrates utilisation.
\end{abstract}

\section{Keywords}

Acid mine drainage - Sulphate-reducing bacteria $•$ Heavy metal removal • Microbial diversity

\section{Introduction}

One of the perils of increasing industrial activity is the current increase in wastewater generation, which poses a threat to both human and aquatic environments. Mining is an example of such activities that has been on the rise, especially in developing nations due to its contribution to the economy of those countries. Mining activities do not utilise a considerable quantity of potable water compared to

E. A. Akinpelu $(\bowtie) \cdot$ E. Fosso-Kankeu $\cdot$ F. Waanders

Water Pollution Monitoring and Remediation Initiatives Research Group, School of Chemical and Minerals Engineering,

North-West University, P. Bag X60001, Potchefstroom, 2520,

South Africa

e-mail: biyipelu@gmail.com

J. O. Angadam · S. K. O. Ntwampe

Bioresource Engineering Research Group (BioERG), Department

of Chemical Engineering, Cape Peninsula University of

Technology, Bellville Campus, Symphony Way, P.O. Box 1906

Cape Town, 7535, South Africa other industries, yet it is the largest producer of toxic wastewater (Corcoran 2010). Over a century, mining has contributed to the well-being of South Africans; hence, the country has many abandoned mine sites that are the primary source of several environmental and health problems (Mhlongo and Amponsah-Dacosta 2016). There are about 5906 abandoned mine sites in South Africa, due to the fact that mining operations cannot be relocated, generating approximately 6 billion tons of mine wastewater (Auditor-General 2009). The extraction of pyrite (sulphide bearing minerals) during mining activities exposes them to the atmosphere which leads to a chain of complex geochemical reactions that produce metal-laden acid mine drainage (AMD) and residual sulphate. Biological treatment with sulphate-reducing bacteria (SRB) is a recognised technology for the treatment of AMD. The ability of the SRB to remediate AMD and thus produce sulphide and bicarbonate in the presence of a suitable electron donor and carbon source aids the treatment of AMD. Culture-dependent and culture-independent approaches have been used to study the microbial diversity of air, soil, water and wastewater (Kamika and Momba 2014). The culture-independent technique has the advantage of direct analysis and classification of microbial populations in a specific environmental sample (Handelsman 2004; Riesenfeld et al. 2004). This study aims at, firstly, profiling the microbial community of SRB in AMD collected from coal mine in Mpumalanga, South Africa, and secondly, to determine the performance of the SRB consortium in a continuously stirred tank reactor (CSTR) containing AMD.

\section{Materials and Methods}

Acid mine drainage (AMD) samples were collected as wastewater from a coal mining site in Mpumalanga Province, South Africa, using standard sampling procedure (EPA 2007). The samples were filtered using $45-\mu \mathrm{m}$ cellulose acetate filters and stored in a polyethylene bottle 
at $4{ }^{\circ} \mathrm{C}$. The physicochemical characteristics of AMD sample at a temperature of $20{ }^{\circ} \mathrm{C}$ had high redox potential $(\mathrm{Eh}=229.5 \mathrm{mV})$ and low $\mathrm{pH}(2.98)$ including turbidity of $145 \mathrm{NTU}$ and electrical conductivity of $7.84 \mathrm{mS} / \mathrm{cm}$. A volume $(100 \mathrm{~mL})$ of AMD was inoculated in a sterile $500-\mathrm{mL}$ bioreactor containing sterilised $400 \mathrm{~mL}$ modified Postgate medium B (Postgate 1984). The constituents of Postgate medium B were $(\mathrm{g} / \mathrm{L}): \mathrm{KH}_{2} \mathrm{PO}_{4} 0.5 ; \mathrm{NH}_{4} \mathrm{Cl} 1.0 ; \mathrm{Na}_{2} \mathrm{SO}_{4}$ 1.0; $\mathrm{CaCl}_{2} \cdot 2 \mathrm{H}_{2} \mathrm{O} 0.1 ; \mathrm{MgSO}_{4} 2.0$; yeast extract 1.0; ascorbic acid 0.1; thioglycolic acid $0.1 ; \mathrm{FeSO}_{4} \cdot 7 \mathrm{H}_{2} \mathrm{O} 0.5$; $\mathrm{NaCl} 26$; sodium lactate $5 \mathrm{~mL}$; and $\mathrm{pH} 7-7.5$. The bioreactor was incubated anaerobically at $35^{\circ} \mathrm{C}$ for 7 days until the colour of the medium changed to black-grey, which indicated a positive growth of the SRB (Ghazy et al. 2011). After 7 days of anaerobic incubation, $100 \mathrm{~mL}$ of inoculum containing numerous isolates was transferred into $400 \mathrm{~mL}$ sterile Postgate medium B in a new sterilised $500-\mathrm{mL}$ bioreactor. The procedure was repeated thrice. All reagents were analytical grade.

The genomic DNA of the SRB sample was extracted and sequencing was done using $341 \mathrm{~F} \quad\left(5^{\prime}-\right.$ CCTACGG GNGGCWGCAG-3') and 785R (5'-GACTACHVGGGTATCTAATCC $-3^{\prime}$ ) targeting V3-V4 of the 16S rRNA genes. The culturable SRB were cultured on nutrient agar supplemented with cycloheximide for bacteria growth, and rose bengal and potato dextrose agar supplemented with chloramphenicol and penicillin-streptomycin, respectively, for fungi growth. The identities of the pure strains and SRB consortium, together with the associated enzymes, were further confirmed in a series of biochemical reactions carried out on a VITEK ${ }^{\circledR} 2$ Compact 30 system (BioMérieux, France) using the colorimetric reagent cards: BCL (Gram-positive spore-forming Bacilli), GN (Gram-negative), GP (Gram-positive) and YST (yeast and yeast-like organisms) as described previously (Akinpelu et al. 2017).

The anaerobic experiments were conducted in a 1-L working volume glass reactor equipped with an overhead stirrer fitted with a two-blade propeller for continuous mixing at $250 \mathrm{rpm}$. The bioreactors containing $800 \mathrm{~mL}$ Postgate medium B were initiated with $10 \%$ inoculum at $35{ }^{\circ} \mathrm{C}$ and $\mathrm{pH}$ around 7 for 21 days with $70 \%$ of the medium being drawn weekly and replaced with fresh Postgate medium B. Sodium bromoethanesulphonate $(3.2 \mathrm{~g} / \mathrm{L})$ was added to the culture during enrichment ( 21 days) to avoid methanogenic activity. After establishing viable microbial population, fresh wastewater-AMD $(10 \% \mathrm{v} / \mathrm{v})$ - was introduced to the reactors operated in continuous mode. The reactors were kept in the continuous mode for 7 days and sampled at predetermined intervals. The reactors were left in a static batch mode for the next 14 days and then sampled.

\section{Results and Discussion}

According to the Illumina MiSeq analysis, a total read count of 133,191 sequences of high quality was obtained from the AMD sample and assigned to different phyla. Overall, 11 phyla with 16 classes were identified, of which phyla Firmicutes $(75.11 \%)$ and unknown microorganisms (24.61\%) were the most abundant followed by Proteobacteria $(0.25 \%)$, Actinobacteria $(0.02 \%)$ and other low-abundance phyla. This study confirmed the dominance of Firmicutes and Proteobacteria in the microbial community of the AMD as was previously reported (Teng et al. 2017; Méndez-García et al. 2015; Kamika and Momba 2014). The biochemical results concurred with the metagenomics analyses, showing dominance of Bacilli in the microbial community; however, most of the species identified in VITEK ${ }^{\circledR}$ are facultative organisms such as Bacillus smithii, B. cereus and B. thuringiensis, as well as $B$. subtilis which grows strictly under anaerobic condition using nitrate as electron acceptor (Nakano and Zuber 1998; Hoffmann et al. 1995). The microbial community showed a wider range of substrate utilisation as expected. Notable amongst the substrates utilised were pyruvate, D-glucose, urea, acetate, and DL-lactate, amongst others.

In this study, the bioreactor was operated at temperature $35 \pm 2{ }^{\circ} \mathrm{C}$ for 42 days, which included an enrichment stage and start-up $\mathrm{pH}$ of 7-7.5. On the 22nd day, raw heavy metal-laden AMD containing $8080 \mathrm{mg} / \mathrm{L}$ was supplied to the system. There was a gradual increase in sulphate reduction up to $1195 \mathrm{mg} / \mathrm{L}$ on the 7 th day in continuous mode which was accompanied by microbial proliferation. This was indicative of a high performance by the SRB consortium, considering the initial sulphate concentration used in the system. The high residual sulphate concentration could be attributed to the low rate of reduction as well as higher concentrations of heavy metals in the raw AMD used. Earlier, Jong and Parry (2003) had shown that higher metal concentration inhibits SRB activities in sulphate reduction due to their toxicity and thus reduces SRB metabolism. In addition, a 50\% reduction in SRB removal efficiency was caused by high copper concentration (Song et al. 1998). A drop in $\mathrm{pH}$ and an increase in redox potential (Eh) were observed at commencement of the continuous operational mode probably due to the introduction of highly acidic with high Eh of the raw AMD. After day 2 of operating in a continuous mode, there were a steady increase in the $\mathrm{pH}$ and a decrease in $\mathrm{Eh}$, an indication of the SRB' adaptation to the new conditions. A similar increase in $\mathrm{pH}$ and a reduction in Eh were observed when AMD was treated in an up-flow anaerobic sludge blanket bioreactor and a packed bed bioreactor (Najib et al. 2017; Dev et al. 2016; Jong and Parry 2003). 
Heavy metals were removed in the form of metal sulphide precipitates. Except $\mathrm{Mg}^{2+}, \mathrm{Zn}^{2+}, \mathrm{As}^{3+}$ and $\mathrm{Cr}^{3+}$ which showed removal percentages of 55, 58, 66 and $69 \%$, respectively, all other metals being removed above $70 \%$. It was reported that $\mathrm{Al}^{3+}, \mathrm{Cu}^{2+}, \mathrm{Ni}^{2+}, \mathrm{Fe}^{2+}$ and $\mathrm{Pb}^{2+}$ are precipitated at $\mathrm{pH}$ below 7 but are completely precipitated at $\mathrm{pH}$ above 9.5 (Kurniawan et al. 2006; Aubé and Zinck 2003). $\mathrm{Cd}^{2+}$ showed the highest removal efficiency (98\%) followed by $\mathrm{Al}^{3+}(97 \%)$. The high metal removal was due to the $\mathrm{pH}$ being below 7 and the presence of facultative heavy metal tolerant $B$. cereus which was identified in the SRB consortium. Some research has reported a complete removal of heavy metals in the range $80-90 \%$ of sulphate reduction operation (Chang et al. 2000; Drury 1999). Therefore, the high sulphate reduction (85\%) and incomplete heavy metal removal in this study can be improved by optimising the process parameters such as $\mathrm{pH}$, initial sulphate concentration and hydraulic retention time (HRT) while maintaining kinetically favourable conditions for the growth of the SRB.

\section{Conclusion}

The microbial profile showed that the phylum Proteobacteria was the predominant phylum constituting the SRB consortium with facultative members of phylum Firmicutes, being determined to be helpful in the removal of heavy metal in the form of precipitation. It was evident that enrichment time (21 days) of the SRB played a major role in the high sulphate reduction and heavy metal precipitation, including the ability of the SRB being able to utilise a wider substrate range as energy sources with the production of several aminopeptidases which act as biocatalyst in raw AMD treatment. This study can thus be helpful in the design of an effective bioprocess for the treatment of sulphate and heavy metal-laden AMD.

\section{References}

Akinpelu, E. A., Adetunji, A. T., Ntwampe, S. K. O., Nchu, F., \& Mekuto, L. (2017). Biochemical characteristics of a free cyanide and total nitrogen assimilating Fusarium oxysporum EKT01/02 isolate from cyanide contaminated soil. Data in Brief, 14, 84-87.

Aubé, B., \& Zinck, J. (2003). Lime treatment of acid mine drainage in Canada (pp. 1-12). Brazil-Canada Seminar on Mine Rehabilitation: Florianópolis.

Auditor-General, S. A. (2009). Report of the Auditor-General to Parliament on a performance audit of the rehabilitation of abandoned mines at the Department of Minerals and Energy. Pretoria.
Chang, I. S., Shin, P. K., \& Kim, B. H. (2000). Biological treatment of acid mine drainage under sulfate-reducing conditions with solid waste materials as substrate. Water Research, 34.

Corcoran, E. (2010). Sick water? The central role of wastewater management in sustainable development: A rapid response assessment. UNEP/Earthprint.

Dev, S., Roy, S., \& Bhattacharya, J. (2016). Understanding the performance of sulfate reducing bacteria based packed bed reactor by growth kinetics study and microbial profiling. Journal of Environmental Management, 177, 101-110.

Drury, W. J. (1999). Treatment of acid mine drainage with anaerobic solid-substrate reactors. Water Environment Research, 71, 1244 1250.

EPA. (2007). EPA guidelines: Regulatory monitoring and testing water and wastewater sampling (E. P. Authority, Ed.). South Australia.

Ghazy, E., Mahmoud, M., Asker, M., Mahmoud, M., Abo Elsoud, M., \& Abdel Sami, M. (2011). Cultivation and detection of sulfate reducing bacteria (SRB) in sea water. Journal of American Science, 7, 604-608.

Handelsman, J. (2004). Metagenomics: Application of genomics to uncultured microorganisms. Microbiology and Molecular Biology Reviews, 68, 669-685.

Hoffmann, T., Troup, B., Szabo, A., Hungerer, C., \& Jahn, D. (1995). The anaerobic life of Bacillus subtilis: Cloning of the genes encoding the respiratory nitrate reductase system. FEMS Microbiology Letters, 131, 219-225.

Jong, T., \& Parry, D. L. (2003). Removal of sulfate and heavy metals by sulfate reducing bacteria in short-term bench scale upflow anaerobic packed bed reactor runs. Water Research, 37, 3379-3389.

Kamika, I., \& Momba, M. N. (2014). Microbial diversity of Emalahleni mine water in South Africa and tolerance ability of the predominant organism to vanadium and nickel. PLOS ONE, 9, e86189.

Kurniawan, T. A., Chan, G. Y. S., Lo, W.-H., \& Babel, S. (2006). Physico-chemical treatment techniques for wastewater laden with heavy metals. Chemical Engineering Journal, 118, 83-98.

Méndez-García, C., Peláez, A. I., Mesa, V., Sánchez, J., Golyshina, O. V., \& Ferrer, M. (2015). Microbial diversity and metabolic networks in acid mine drainage habitats. Frontiers in Microbiology, 6.

Mhlongo, S. E., \& Amponsah-Dacosta, F. (2016). A review of problems and solutions of abandoned mines in South Africa. International Journal of Mining, Reclamation and Environment, 30, 279-294.

Najib, T., Solgi, M., Farazmand, A., Heydarian, S. M., \& Nasernejad, B. (2017). Optimization of sulfate removal by sulfate reducing bacteria using response surface methodology and heavy metal removal in a sulfidogenic UASB reactor. Journal of Environmental Chemical Engineering.

Nakano, M. M., \& Zuber, P. (1998). Anaerobic growth of a "strict aerobe" (Bacillus subtilis). Annual Review of Microbiology, 52, $165-190$.

Postgate, J. (1984). The sulphate-reducing bacteria. Cambridge: Cambridge University Press.

Riesenfeld, C. S., Schloss, P. D., \& Handelsman, J. (2004). Metagenomics: Genomic analysis of microbial communities. Annual Review of Genetics, 38, 525-552.

Song, Y.-C., Piak, B.-C., Shin, H.-S., \& La, S.-J. (1998). Influence of electron donor and toxic materials on the activity of sulfate reducing bacteria for the treatment of electroplating wastewater. Water Science and Technology, 38, 187-194.

Teng, W., Kuang, J., Luo, Z., \& Shu, W. (2017). Microbial diversity and community assembly across environmental gradients in acid mine drainage. Minerals, 7, 106. 